\title{
MITIGATION OF METAL ION POLLUTION FROM INDUSTRIAL WASTE WATER USING WASTE WOOL
}

\author{
GARIMA PRAJAPAT* \\ Department of Chemistry, Government Engineering College Bikaner, Bikaner-334001, Rajasthan, India \\ garimagoel4@gmail.com \\ DR. PRAVEEN PUROHIT \\ Department of Chemistry, Government Engineering College Bikaner, Bikaner-334001, Rajasthan, India \\ rajpurohitpraveen@yahoo.com
}

\begin{abstract}
A study on the adsorption of copper (II) ions from the aqueous solution on waste wool had been carried out to analyze the adsorption capacity of waste wool, thereby aiming towards mitigation of metal ion pollution in industrial waste water. The effect of varying concentration of copper ions and varying time period, was studied on fixed weight of waste wool. The initial and final concentration of copper ions was measured by conductometric and spectrophotometric methods. Adsorption data were modeled with the langmuir and freundlich adsorption isotherms. The isotherm and first order equation were found to be applicable. Removal of metal ions using industrial waste wool is found to be favourable. Thus the work can be extended to study various physico-chemical parameters for removal of copper (II) ions from industrial effluents using waste wool. A later work can be involved where the waste wool adsorption parameter can be further utilized for composite ceramic products.
\end{abstract}

Keywords: Copper Ions; Waste Wool; Langmuir \& Freundlich Adsorption Isotherm

\section{Introduction}

Water pollution has emerged as a major environmental problem due to rapid industrialization and urbanization. Many industries such as metal finishing, battery manufacturing, mining, electroplating, automotive, tanning, textile manufacturing, fertilizer manufacturing, release various concentrations of heavy metals like Cadmium, Nickel, Copper etc. in effluent water. Unlike organic pollutants, metal ions are nondegradable and are thus persistent in the environment ${ }^{1}$. Copper toxicity is known to cause severe health disorders like anorexia, allergies, anxiety, premenstrual syndrome, migraine, depression and many others.

It is therefore very essential that these heavy metals should be removed from the industrial effluents and waste water, in order to solve heavy metal pollution in environment. Some of the important technologies involving removal of heavy metal ions from waste water include solvent extraction, reverse osmosis, chemical precipitation, ion exchange, cementation and biosorption ${ }^{2-4}$. But most of these technologies involve high capital costs and partial metal ion removal ${ }^{5}$. 
Adsorption at solid substrate is a very effective method of removal of even very low levels of heavy metals from their aqueous solutions. Wool fibers contain mainly Keratin Protein, which is why wool acts as a good adsorbent material for various colors and dyes. Woolen Industries release a large amount of waste wool which acts as an environmental nuisance and pollutant. Thus waste wool can be conveniently utilized as an adsorbent material for adsorption of heavy metal ions from industrial effluents.

The present work involves study of adsorption of copper ions on waste wool from the aqueous solution, to analyze the adsorption capacity of waste wool. Utilization of waste wool through adsorption method can provide a very effective yet economical method for treatment of waste water. The study involves the influence of specific process parameters such as initial metal ion concentration and contact time for the maximum removal of copper (II) ions from aqueous solution.

\section{Materials and Methods}

\subsection{Materials}

The stock solutions of copper (II) ions were prepared by dissolving copper sulfate (A.R.) in distilled water.

\subsection{Adsorbent}

Scoured raw waste wool was obtained from local woolen industry situated in Karni Nagar Industrial Area, Bikaner. In order to remove any sand or dust particles, the wool was cleaned with hot distilled water and dried at room temp.

\subsection{Experimental method}

The adsorption experiments were carried out by batch equilibrium method. A stock solution of adsorbate containing $1000 \mathrm{ppm}$ of copper(II) ions was prepared by dissolving $\mathrm{CuSO}_{4} .5 \mathrm{H}_{2} \mathrm{O}$ (A.R.) in distilled water. $\mathrm{Cu}$ (II) ion solutions of varying concentration from $50 \mathrm{ppm}$ to $500 \mathrm{ppm}$ were prepared from dilution of stock solution. Sample solution of each concentration $(40 \mathrm{~mL})$ was mixed with $200 \mathrm{mg}$ of adsorbent wool. Samples were taken at different time intervals for the analysis of residual metal concentration in solution. The adsorbent-metal ion mixture was filtered for analysis of unadsorbed metal in the solution. Analysis of equilibrium metal ion concentration was done separately by using

- Digital conductivity meter (Model 611-E)

- Double beam Uv/Vis.Spectrophotometer (Model 2203)

All the experiments are carried out at a $\mathrm{pH}$ of 6.4 and temperature $303 \mathrm{~K}$.

$\%$ Removal of heavy metal from solution was calculated by the following Eq. (1)

$$
\% \text { Removal }=\frac{\left(C_{o}-C_{e}\right) \times 100}{C_{o}} .
$$


Where $C_{o}(p p m)$ is the initial metal ion concentration. $C_{e}(p p m)$ is the equilibrium metal ion concentration in solution at time $t$. The adsorption capacity or the metal uptake $\left(\mathrm{q}_{\mathrm{e}}\right)$ was calculated by the following Eq.(2)

$$
q_{e}=\frac{\left(C_{o}-C_{e}\right) V}{1000 W}
$$

Where $\mathrm{q}_{\mathrm{e}}(\mathrm{mg} / \mathrm{g})$ is the amount of the total adsorbed heavy metal ion, $\mathrm{V}(\mathrm{L})$ is the volume of solution, $\mathrm{W}(\mathrm{g})$ is the adsorbent weight.

\section{Results and Discussions}

The results of conductometric and spectrophotometric studies confirmed each other. The equilibrium metal ion concentrations were obtained from the linear plots between conductivity versus concentration and absorbance versus concentration of copper sulfate solutions shown in figure no. 1 and 2 respectively.

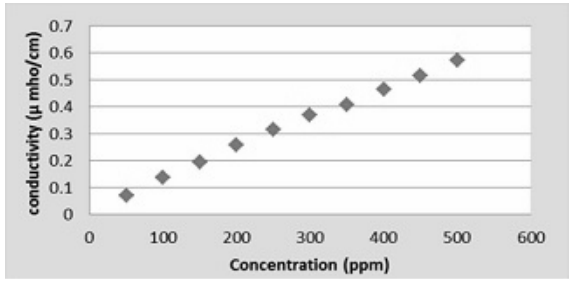

Fig. 1 Plot of Conductivity versus concentration

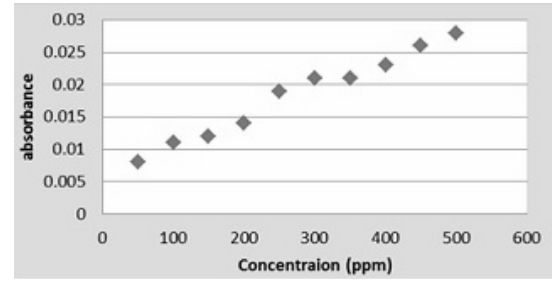

Fig. 2 Plot of absorbance versus concentration

\subsection{Effects of contact time}

The variation of equilibrium metal ion concentration and \% metal removal with contact time are represented in figure no. 3 and 4 respectively.

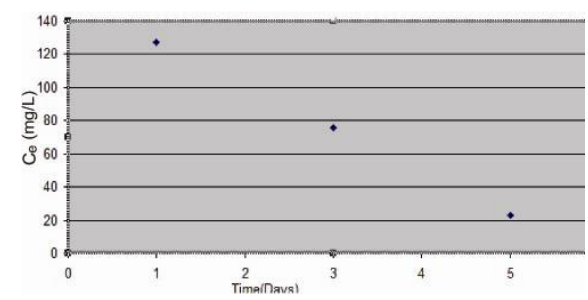

Fig. 3 Ce Versus time

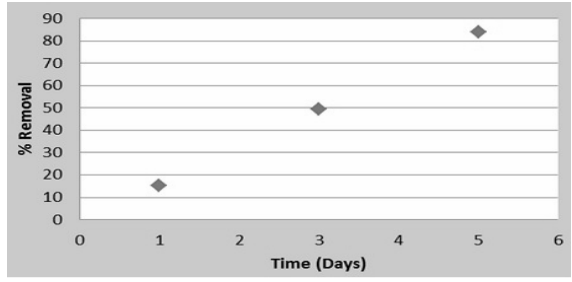

Fig. 4 Plot of \% removal versus time

The removal of $\mathrm{Cu}$ (II) ions increase with increase in time. There is steep increase in the adsorption which shows that adsorption is in the initial stage. The rate of \% metal removal increases due to larger surface area of the adsorbent available for the adsorption of metal ions ${ }^{6}$. 


\subsection{Effect of initial metal ion concentration}

Fig.5 shows the variation of $\%$ removal with initial metal ion concentration. It is easily revealed that the \% removal of metal ions is high at lower concentrations of metal ion, while it decreases gradually with the increase in metal ion concentration. This clearly indicates that the metal uptake mechanism is dependent on the initial heavy metal ion concentration. At lower metal ion concentrations the ratio of initial number of copper ions to the available surface area is low. As the metal ion concentration increases, the available sites of adsorption becomes fewer.

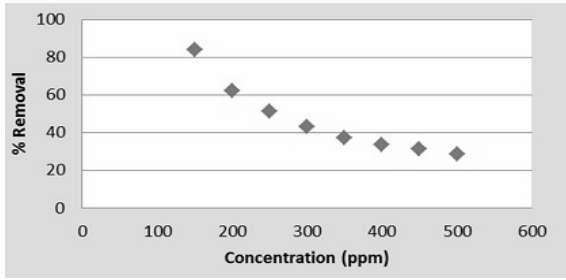

Fig. 5 Plot of \% removal versus initial metal ion concentration

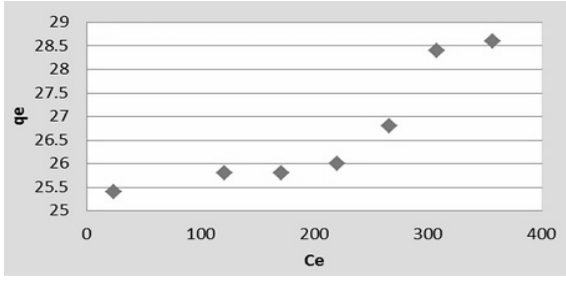

Fig. 6 Plot of metal uptake versus Ce

Fig. 6 shows metal uptake versus equilibrium metal ion concentration.

The curve is smooth and continuous leading to saturation, suggesting the possible monolayer formation of $\mathrm{Cu}$ (II) ions on the surface of adsorbent wool ${ }^{7-9}$.

\subsection{Adsorption isotherms}

In order to successfully represent the equilibrium adsorption behavior, the study of adsorption isotherm is essential in selecting the adsorbent for the removal of metal ions. The experimental data was thus analyzed according to linear forms of Langmuir and Freundlich isotherms.

\subsection{Langmuir isotherm}

Batch isotherm data fitted into the linear form of the Langmjuir isotherm according to the Eq. 3

Langmuir Equation: $\quad \frac{C_{\mathrm{e}}}{q_{\mathrm{e}}}=\frac{1}{b Q}+\frac{C_{\mathrm{e}}}{Q}$

Where $\mathrm{C}_{\mathrm{e}}(\mathrm{mg} / \mathrm{L})$ is the equilibrium metal ion concentration and $\mathrm{q}_{\mathrm{e}}(\mathrm{mg} / \mathrm{g})$ is the amount of copper sorbed per unit weight of sorbent, or metal uptake. $\mathrm{Q}$ and $\mathrm{b}$ are the Langmuir constants indicating adsorption capacity and energy of adsorption respectively. The linear plot of $\mathrm{C}_{\mathrm{e}} / \mathrm{q}_{\mathrm{e}}$ versus $\mathrm{C}_{\mathrm{e}}$ by the data obtained from conductometric and spectrophotometric analysis are given in fig (7) and (8) respectively. 


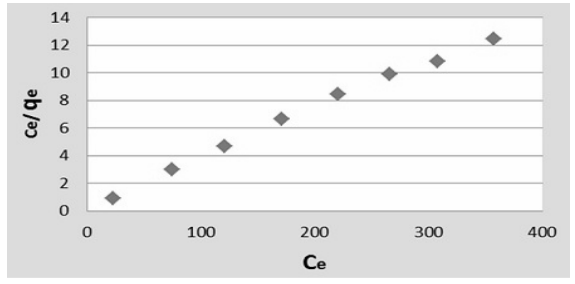

Fig. 7 Langmuir isotherm (Data obtained from conductometric studies)

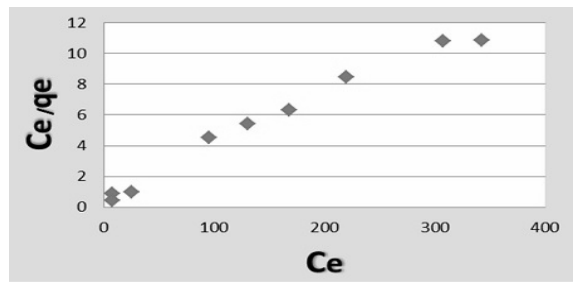

Fig. 8 Langmuir isotherm (Data obtained from spectrophotometric studies)

The figures indicate the applicability of Langmuir isotherm to the adsorption process. The linearity shows that there is formation of monoionic layer of the adsorbate and any further formation of multiple layer is hindered due to the interaction between the metal ions on the surface of wool and in the aqueous solution ${ }^{10-12}$. The values of various parameters obtained by regression are given in Table (1)

Table 1 - Value of Langmuir Constants

\begin{tabular}{cccrc}
\hline Temp. & Statistical Parameter & \multicolumn{2}{c}{ Langmuir Constants } & $R_{\mathrm{L}}$ \\
& $\mathrm{r}^{2}$ & $Q(\mathrm{mg} / \mathrm{g})$ & $b(\mathrm{~L} / \mathrm{mg})$ & \\
\hline $303 \mathrm{~K}$ & 0.9948 & 28.8 & 0.065 & 0.235 \\
\hline
\end{tabular}

The Langmuir constants obtained indicate that wool serves as an effective and efficient adsorbent material for copper ions with high adsorption capacity and endothermic nature of processes involved. The favorability of adsorption process is confirmed by the value of separation factor $R_{L}$ obtained which is given by Eq. 4

$$
R_{\mathrm{L}}=\frac{1}{1+b C_{\mathrm{o}}}
$$

Where $\mathrm{C}_{\mathrm{o}}$ is the optimum initial metal ion concentration (ppm) and $\mathrm{b}$ is the Langmuir constant. The $\mathrm{R}_{\mathrm{L}}$ values were found to be between 0 and 1 and confirm that the adsorption of copper is favorable $\mathrm{e}^{13-14}$.

\subsection{Freundlich isotherm}

Fig. (9) and (10) represent Freundlich isotherms formed by the data obtained through conductometric \& spectrophotometric methods respectively. 


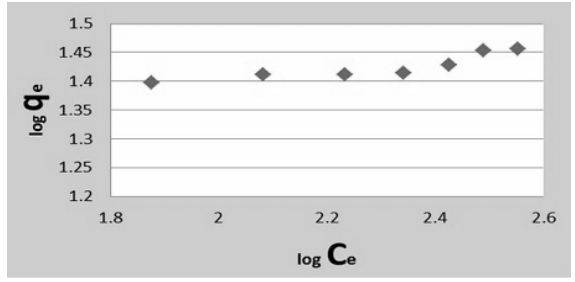

Fig. 9 Freundlich isotherm (Data obtained from Conductometric studies)

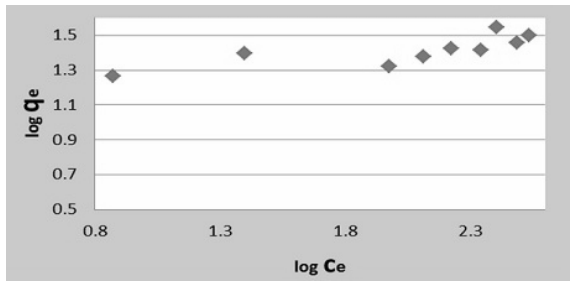

Fig. 10 Freundlich isotherm (Data obtained from spectrophotometric studies)

The linear form of the Freundlich isotherm was applied in the form of Eq. (5)

Freundlich Eq.

$$
\log q_{\mathrm{e}}=\log K+\frac{1}{n} \log C_{\mathrm{e}}
$$

Where $\mathrm{q}_{\mathrm{e}}$ and $\mathrm{C}_{\mathrm{e}}$ have their usual meaning. Freundlich parameters $\mathrm{K}$ and $\mathrm{n}$ represent adsorption capacity and intensity of adsorption respectively.

The values of $\mathrm{K}$ and $\mathrm{n}$ were determined by regression of experimental data and are given in Table (2)

Table 2 - Value of Freundlich Constants

\begin{tabular}{cccc}
\hline Temp. & Statistical Parameter & \multicolumn{2}{c}{ Freundlich Constants } \\
& $\mathrm{r}^{2}$ & $K$ & $n$ \\
\hline $303 \mathrm{~K}$ & 0.8769 & 23.1 & 6.25 \\
\hline
\end{tabular}

The values show that adsorption capacity of wool for copper ions is quite high. The intensity of adsorption is an indicative of the bond energies between copper ion and adsorbent and the value of $\mathrm{n}$ is greater than one indicating a favorable adsorption ${ }^{15-16}$. The present finding are in good agreement with the findings of Treybal ${ }^{17}$ who mathematically evaluated values of $\mathrm{n}$ for a number of mass transfer operations of systems and reported that values of $\mathrm{n}$ between 1 and 10 would represent beneficial adsorption.

\section{Conclusions}

The following conclusions can be deduced from the present studies

(i) The adsorption process is a function of initial metal ion concentration. The percentage removal of metal ions increases with decrease in initial concentration of metal ion.

(ii) The percentage removal of metal ions increases with increase in the contact time.

(iii) The experimental data correlated reasonably well by the Langmuir and Freundich adsorption isotherms. The results indicate strong adsorption capacity of adsorbent for the metal ions and the formation of unimolecular layer of adsorbate. 
Waste wool could be thus used as an effective adsorbent for the design of waste water treatment plants for removal of copper ions from industrial effluents. The study also helps to suggest a solution towards the waste management of wool for a number of woolen industries in a positive manner.

\section{References}

1. K.V. Gupta, M.Gupta and S.Sharma, Process development for the removal of lead and chromium from aqueous solutions using red mud-an aluminum industry waste, Water Res., 35, 1125-1134, (2001)

2. Kaewsarn P, Chemosphere, 47, 1081 (2002).

3. Kim D S, J Hazard Matter, B106, 67 (2004).

4. Dean J G, Bosqui F L \& Lanouette K H, Environ Sci Technol, 6, 518 (1972).

5. Wilde E Q \& Benemann J R, Biotechnol Adv, 11, 781 (1993).

6. Singh D K \& Srivastava B, Indian J Chem Technol, 8, 133 (2001).

7. Singh D K, Gerg S K \& Bharadwaj R K, Indian J Environ Protec, 21, 604 (2001).

8. Khatri S D \& Singh M K, Indian J Chem Technol, 6, 112 (1999).

9. Desai M, Dogra A, Vora S. Bahadur P \& Ram R N, Indian J Chem, 36, 938 (1997).

10. Weber T W \& Chakravorti, J Am Inst Chem Eng, 2, 228 (1974).

11. Hall K R, Eagleton L C, Acrivos A \& Vermeulen T, Ind Eng Chem Fund, 5, 212 (1966)

12. Kannan N, Indian J Env Portec, 11(7), 514 (1991)

13. S.Arivoli, M.Viji Jain and T. Rajachandrasekar, Mat. Sci. Res. India, 3, 241-250 (2006)

14. S. Arivoli and M.Hema, Intern. J. Phys. Sci., 2, 10-17 (2007)

15. S.Arivoli, B.R. Venkatraman, T.Rajachandrasekar, and M.Hema, Res. J. Chem. Environ., 1, 770-78 (2007)

16. S. Arivoli, K.Kalpana, R.Sudha and T. Rajachandrasekar, E.J. Chem. 4, 238-254 (2007)

17. Treybal R, Mass Transfer Operations (McGraw Hill, New York), 1980 